\title{
Assembly and Transport Properties of Nanoscale Biopolyelectrolyte Multilayers
}

\author{
Jaebum Park ${ }^{1}$ and Michael J. McShane ${ }^{1,2, * \mathbb{D}}$ \\ 1 Department of Materials Science and Engineering, Texas A\&M University, \\ College Station, TX 77843-3120, USA; jbpark@tamu.edu \\ 2 Department of Biomedical Engineering, Texas A\&M University, College Station, TX 77843-3120, USA \\ * Correspondence: mcshane@tamu.edu; Tel.: +1-1979-845-7941
}

check for updates

Citation: Park, J.; McShane, M.J. Assembly and Transport Properties of Nanoscale Biopolyelectrolyte Multilayers. Coatings 2021, 11, 1024 https://doi.org/10.3390/coatings 11091024

Received: 24 July 2021

Accepted: 25 August 2021

Published: 26 August 2021

Publisher's Note: MDPI stays neutral with regard to jurisdictional claims in published maps and institutional affiliations.

Copyright: (c) 2021 by the authors. Licensee MDPI, Basel, Switzerland. This article is an open access article distributed under the terms and conditions of the Creative Commons Attribution (CC BY) license (https:/ / creativecommons.org/licenses/by/ $4.0 /)$.

\begin{abstract}
Nanoscale coatings are attractive for managing the biological/material interface as well as for transport control in medical device applications. Construction of biologically derived and mimicking polyelectrolyte multilayers (BioPEMs) and their chemically crosslinked derivatives was evaluated at the nanometer scale and the glucose mass transfer properties were characterized in a physiological environment. Glucose diffusivity through all the BioPEMs was found to be three to four orders of magnitude lower than that of bare substrate. In contrast, permeation rates $(d C / d t)$ were significantly higher than when compared to films comprising the same number of bilayers of synthetic materials-poly(acrylic acid)/poly(allylamine hydrochloride). Crosslinked BioPEMs exhibited decreased diffusivity of glucose up to $51 \%$ compared to native BioPEMs. These findings provide fundamental insight into the transport properties of BioPEM coatings that may be useful in maximizing biomimetic properties while also controlling permeation of small molecules in applications such as sensors, filtration, and drug delivery systems.
\end{abstract}

Keywords: polyelectrolyte multilayer; biocompatibility; transport control; biopolymers; polysaccharides; diffusion limiting; biosensors; drug delivery

\section{Introduction}

The development of biomedical devices requires the proper interface between substrate and biological environment. Thus, there are special requirements for selecting materials to be used in biomedical applications. For example, for biosensors that employ sensitive proteins that serve to bind the target molecules, a suitably supportive matrix is required for immobilization of the biological elements. Then, a gentle process for introduction of the biological receptor must be developed. In many cases where it is desirable or necessary to control the diffusion of molecules into and out of the matrix, such as in enzymatic biosensors and drug delivery systems, a transport-limiting membrane (often a coating) may need to be applied to the surface, especially when enzymatic systems are involved. This enables the "tuning" of the permeation rate, so as to achieve the appropriate balance between diffusion and the binding/consuming reactions. The system may then achieve a depletion of substrate or local generation of product that is then proportional to the concentration of a target analyte [1]. If the device is to be implanted or otherwise in contact with biofluids, the host response to the foreign materials that is triggered by protein adsorption must be minimized while still maintaining control over the mass transport $[2,3]$. Masking implants with surface coatings is a typical strategy aimed at limiting protein adsorption so as to enhance biocompatibility. In particular, significant protein adsorption may foul surfaces which would otherwise interfere with molecular flux, resulting in changes in sensor responses or drug release profiles.

Manufacturing approaches using self-assembly methods, such as layer-by-layer (LbL) self-assembly, are attractive for efficient and effective micro/nanoscale coatings. Polyelectrolyte multilayers may be formed using $\mathrm{LbL}$ in mild aqueous conditions and using a broad 
spectrum of candidate materials, and may achieve high precision, making them particularly attractive for use in biomedical applications [4-6]. The LbL assembly process is simple, self-regulating, precise, and scalable, enabling formation of films with total thickness from nanometers to micrometers scale with a resolution of a few nanometers [7]. Films may comprise multiple layers containing alternately charged molecules, and may be deposited as coatings on virtually any charged substrate. This approach is broadly applicable, implying that there is no fundamental limitation on the choice of coating components other than sufficient charge under the deposition conditions such that multiple ionic bonds are formed with the substrate or pre-deposited materials. The technique has been applied successfully to many types of molecules, from charged polymers to small molecular dyes [8-12], and has been used to construct films containing organized protein multilayers [10], charged nanoparticles [8,12], bionanoreactors [13], and sensors [10,14,15]. It has also been shown that the activity of enzymes is protected from degradation in multilayers with polyions [16].

The demand for nanometer-scale control over the properties and functions of a biointerface has increased in the past few decades, as they have been noted to influence molecular cell and tissue events, including cell adhesion [17-21], protein adsorption [22-24], and host response to foreign materials [25,26]. One of the crucial properties of biological systems that depend strongly on this biological matrix is the transport behavior of membranes at the material interfaces. For example, implantable chemical sensing and drug release systems require diffusion-limiting coatings to act as transport barriers for specific molecules (Scheme 1) [27-31]. However, the transport behavior at the interface of these coatings can vary widely as a result of their interactions with the composition of the coating.

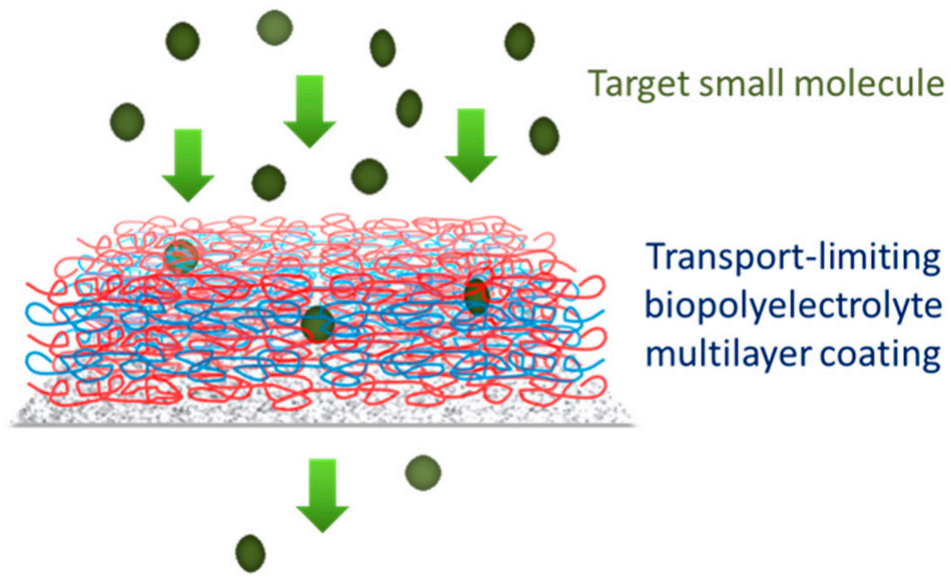

Scheme 1. Diffusion of small molecules through biopolyelectrolyte multilayer coatings.

Considerable effort has been devoted towards the functionalization of commonly used biomaterial surfaces, adding new biological functionality, and to rendering them more "biomimetic" (i.e., the self-organization of natural matrices) [32,33]. "Biopolyelectrolytes" -charged polymers with natural origin or inspiration-such as alginate, chitosan, heparin, dextran sulfate, poly(L-lysine), and poly(L-glutamic acid), have been carefully explored for biomedical applications, including drug delivery, biosensors, and tissue engineering, as biocompatible and, in some cases, also biodegradable materials [32,33]. The wide range of candidate polyelectrolytes combined with the precision processing advantages offered by polyelectrolyte multilayer (PEM) coatings-localized delivery and spatial confinement, as well as the ability to protect against external stresses and exposure to harsh chemical conditions - considerably expand the possibilities for PEM films to address biological problems [32]. Transport properties of glucose (used as a model small molecule) through synthetic polyelectrolyte multilayers have been studied in previous reports $[24,33]$.

Crosslinking of PEMs is known to impart greater stability upon the films [34-36]. However, no comparison of small molecule diffusion before and after crosslinking of biopolyelectrolyte multilayer (BioPEM) films has, to our knowledge, been performed. In 
this work, native and post-treated (crosslinked) nanostructured multilayer films comprising combinations of bio-mimetic natural and synthetic polyelectrolytes were characterized, and the glucose transport properties of the films were measured for the first time.

\section{Materials and Methods}

Glucose, glucose oxidase, peroxidase, o-dianisidine, $\mathrm{NaCl}, \mathrm{NaOH}, \mathrm{HCl}$, poly(L-lysine hydrobromide) (PLL, $\left.M_{w}=15,000-30,000\right)$, and alginic acid sodium salt from brown algae (Alg, low viscosity) were purchased from Sigma (New York, NY, USA). Chitosan (Chi, $\left.M_{w} \sim 50,000\right)$ and poly(L-glutamic acid sodium salt) (PGA, $\left.M_{v}=15,000-50,000\right)$ were purchased from Aldrich (New York, NY, USA). Heparin sodium salt (Hep), dextran sulfate sodium salt ( $\left.D S, M_{w}>500,000\right)$, and $N$-(3-Dimethylaminopropyl)- $N^{\prime}$-ethylcarbodiimide hydrochloride (EDC) were purchased from Sigma-Aldrich. $N$-hydroxysuccinimide (NHS) was obtained from Toronto Research Chemicals Inc. (North York, ON, Canada).

The porous alumina supports (Anodisc 25, $60 \mu \mathrm{m}$ thick, $0.02 \mu \mathrm{m}$ pore diameter) were purchased from Whatman Ltd. (London, UK). Deionized water $(>18.2 \mathrm{M} \Omega \mathrm{cm}$ ) was used for preparation of polyelectrolyte solutions and rinsing. The $\mathrm{pH}$ of the polyelectrolyte solutions was adjusted with either $\mathrm{NaOH}$ or $\mathrm{HCl}$ as needed.

Electrostatic interactions between polyanions (Alg, DS, Hep, and PGA) and polycations (PLL and Chi) were exploited to construct multilayer coatings by alternating exposure to oppositely charged materials until deposition of the desired number of layers was achieved. First, an alumina support was mounted within an open-face filter holder (Pall Co.). The process of depositing PLL-containing PEMs then began by presenting the exposing side of the alumina disc to a solution of polyanion $(1 \mathrm{mg} / \mathrm{mL})$ dissolved in phosphate-buffered saline (PBS, pH 7.4) for $10 \mathrm{~min}$. The alumina support with a single layer of adsorbed polyelectrolyte was then rinsed with PBS for 1 min before submersion into PLL ( $1 \mathrm{mg} / \mathrm{mL}$ ) in PBS for $10 \mathrm{~min}$, again followed by PBS rinse. Chitosan-based PEMs were produced using similar steps, except $0.15 \mathrm{M} \mathrm{NaCl}$ solutions adjusted to $\mathrm{pH} 5.5$ were used to dissolve the polyelectrolytes and also for the rinse steps to maintain ionic strength of the multilayers. This process was repeated for all combinations (PGA/PLL, DS/PLL, Alg/PLL, Hep/PLL, PGA/Chi, DS/Chi, Alg/Chi, and Hep/Chi) until the target number of bilayers (i.e., 6.5 or 7) was achieved. After deposition of all layers, films were dried with $\mathrm{N}_{2}$ prior to ellipsometric measurements.

The process of BioPEM formation was monitored using a quartz crystal microbalance (QCM, QCM200, Stanford Research Systems, Inc., Sunnyvale, CA, USA). Gold-coated AT-cut quartz crystals with a fundamental resonance frequency of $5 \mathrm{MHz}$ were cleaned by immersion into a 1:1:5 solution of $\mathrm{H}_{2} \mathrm{O}_{2}(30 \% w / w), \mathrm{NH}_{4} \mathrm{OH}(25 \% w / w)$, and deionized water heated to a temperature of about $75^{\circ} \mathrm{C}$ for $5 \mathrm{~min}$, followed by an immediate rinse with deionized water and drying with $\mathrm{N}_{2}$. The quartz crystal was then loaded into the QCM liquid flow cell. Each solution of biopolyelectrolyte described above was alternatively introduced into the flow system after rinsing and stabilizing the QCM frequency until the desired number of layers was reached. Frequency shifts were measured before, during, and after exposure to the biopolyelectrolyte solutions, and measurements were performed under continuous flow at $50 \mu \mathrm{L} / \mathrm{min}$. As described previously, the mass was determined from the measured frequency using Sauerbrey's equation [37].

Static $\left(\theta_{\text {static }}\right)$ contact angle $(C A)$ measurements of deionized water droplets at the nanofilm-air interface on the porous alumina substrate were measured by a goniometer (CAM200, KSV Instruments, Ltd., Helsinki, Finland) at room temperature. Thickness and refractive index of the nanofilms on the porous alumina substrate were measured by ellipsometry (EP3-SE, Nanofilm, Inc., Tokyo, Japan) with an incident angle of $54^{\circ}$ and a wavelength of $532 \mathrm{~nm}$ in a four-zone compensator mode to minimize errors in surface homogeneity. All measurements were performed before and after crosslinking of BioPEMs. For all refractive index and thickness measurements, at least three different films were prepared with the same composition. The refractive index and thickness were then measured at each of five different, randomly selected locations on each prepared 
sample. The values reported are the mean and $95 \%$ confidence interval of the mean for 15 measurements.

Crosslinking was conducted on the pre-deposited films which contained $-\mathrm{COOH}$ in the polyanions and $-\mathrm{NH}_{2}$ in the polycations (i.e., $\mathrm{Alg} / \mathrm{PLL}, \mathrm{Hep} / \mathrm{PLL}, \mathrm{PGA} / \mathrm{PLL}, \mathrm{Alg} / \mathrm{Chi}$, $\mathrm{Hep} / \mathrm{Chi}$, and PGA/Chi). Crosslinking reactions were performed on porous alumina supports and on silicon substrates (for ATR-FTIR measurements). EDC (200 mM) and sulfo-NHS (50 mM) were dissolved in a $0.15 \mathrm{M} \mathrm{NaCl}$ aqueous solution adjusted to $\mathrm{pH} 5.5$. The substrate with pre-deposited nanofilms was immersed in the EDC/NHS solution for $12 \mathrm{~h}$ at $4{ }^{\circ} \mathrm{C}$ as previously reported [38].

Diffusivity of glucose through BioPEMs was measured before and after crosslinking using a custom experimental system and associated analysis described in our previous report [24]. Briefly, three Side-Bi-Side diffusion cells (Permegear, Inc., Hellertown, PA, USA) were used in parallel. In each case, a cell comprises both a permeate chamber and a feed chamber. The alumina support, coated with the film of interest, was placed between the chambers. The feed chamber contained $0.4 \mathrm{mM}$ glucose while the permeate chamber was filled with PBS. Temperature of the water-jacketed diffusion cells was maintained at $27^{\circ} \mathrm{C}$ with a water circulator. Liquid was synchronously withdrawn from both feed and permeate chambers using a high-precision multi-channel pump to maintain equal volume. The sampled solutions were transferred to a 96-well plate through a computercontrolled fraction collector running custom-programmed LabVIEW virtual instruments. Glucose concentration of the sampled wells was determined with an enzyme-linked assay comprising a mixture of glucose oxidase, peroxidase, and $o$-dianisidine. This was used to generate a color change in the absorbing dye, which was then measured using a plate reader (Infinite F200, Tecan, Ltd., Dorset, UK) after $30 \mathrm{~min}$ of incubation at $37^{\circ} \mathrm{C}$ [39]. At least three nanofilms of the same composition were used in independent diffusion measurements for statistical purposes.

\section{Results and Discussion}

According to the mass increases observed by quartz crystal resonator measurements, all combinations of polyelectrolytes successfully yielded nanofilms with predictable patterns of growth following the number of layers (Figure 1). In particular, films comprising PLL complexed with alginate (Alg/PLL), dextran sulfate (DS/PLL), and poly(glutamic acid) (PGA/PLL) exhibited exponential film growth over the 14-layer deposition cycle. According to previous reports, these growth profiles are typically observed in cases where significant inter-diffusion of polyelectrolytes is present, as is common for PLL-containing PEMs $[40,41]$.

Intuitively, the surface hydrophobicity and thickness of multilayer films are both key factors influencing molecular transport through multilayer films. Thickness is a direct determinant of permeation rate and is required to calculate the diffusion coefficient, while surface wettability affects the permeability of the film to target species [42,43]. Thus, these two properties were determined for each material combination as part of the investigation of characteristics that may correlate with the diffusion of small molecules (e.g., glucose). Average thickness values of all Chi-based films varied significantly with their compositions (41-126 nm), while thicknesses of PLL-based multilayers were more narrowly clustered in the range of 103 to $140 \mathrm{~nm}$ (Table 1). 

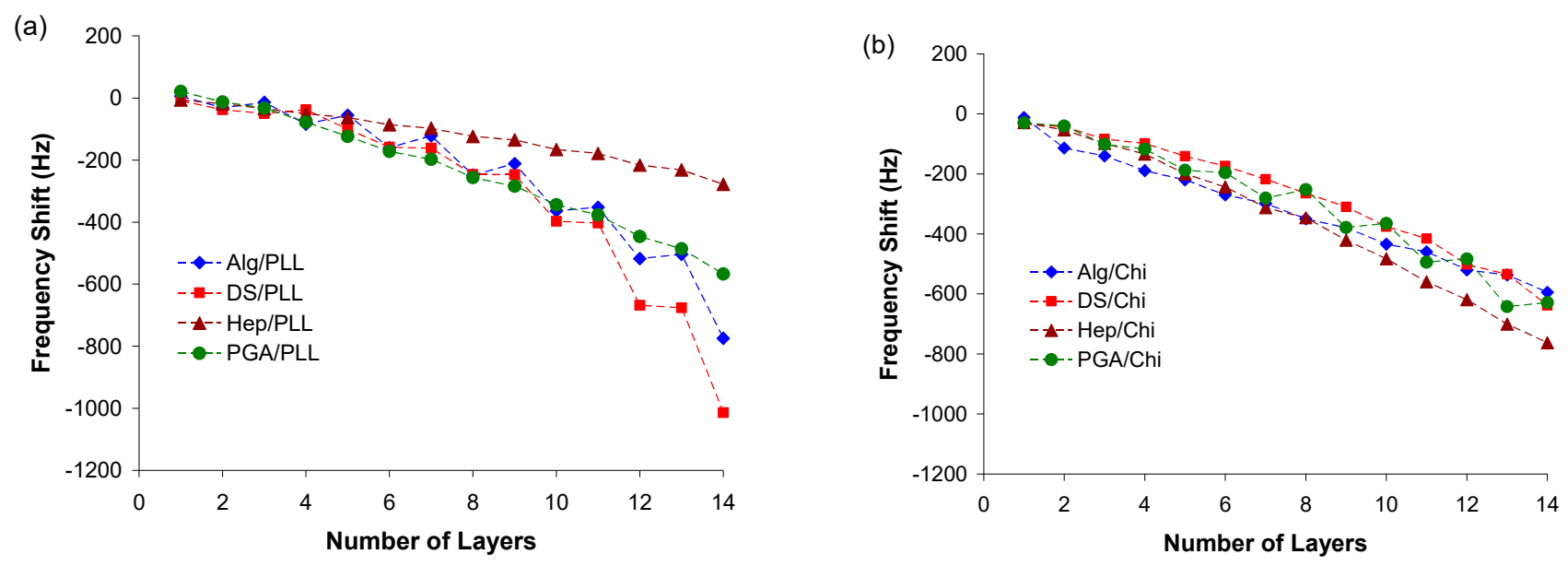

Figure 1. Cumulative QCM frequency shifts $(\Delta F)$ of (a) polyanions/PLL adsorption and (b) polyanions/Chi adsorption on the gold-coated quartz crystal electrode. An odd number of layers represents either a PLL or Chi terminal layer and an even number of layers represents a polyanion terminal layer.

Table 1. Static contact angle $(C A)$, thickness $(L)$, and measurements of 6.5 and 7 bilayers of each BioPEM component ${ }^{a}$.

\begin{tabular}{ccccc}
\hline \multirow{2}{*}{ Composition } & \multicolumn{2}{c}{$\boldsymbol{C A}\left(^{(}\right)$} & \multicolumn{2}{c}{$\mathbf{( n m )}$} \\
\cline { 2 - 5 } & $\mathbf{6 . 5}$ Bilayers & 7 Bilayers & 6.5 Bilayers & 7 Bilayers \\
\hline [Alg/Chi] & $39( \pm 4.8)$ & $44( \pm 5.9)$ & $41( \pm 5.0)$ & $54( \pm 9.1)$ \\
[DS/Chi] & $13( \pm 1.4)$ & $18( \pm 1.6)$ & $78( \pm 11.6)$ & $101( \pm 5.7)$ \\
{$[$ Hep/Chi] } & $14( \pm 1.0)$ & $16( \pm 4.2)$ & $117( \pm 4.2)$ & $126( \pm 8.6)$ \\
[PGA/Chi] & $31( \pm 1.5)$ & $31( \pm 2.1)$ & $41( \pm 5.8)$ & $72( \pm 9.1)$ \\
[Alg/PLL] & $61( \pm 3.7)$ & $58( \pm 1.7)$ & $140( \pm 7.2)$ & $133( \pm 12.1)$ \\
[DS/PLL] & $8( \pm 1.4)$ & $17( \pm 1.6)$ & $134( \pm 4.9)$ & $135( \pm 4.0)$ \\
[Hep/PLL] & $41( \pm 2.5)$ & $52( \pm 1.2)$ & $103( \pm 2.6)$ & $117( \pm 4.1)$ \\
[PGA/PLL] & $70( \pm 1.9)$ & $72( \pm 0.4)$ & $103( \pm 19.9)$ & $118( \pm 14.9)$ \\
\hline
\end{tabular}

a $95 \%$ confidence intervals are shown in parentheses $(\mathrm{n}=3$ for $\mathrm{CA} ; \mathrm{n}=15$ for $\mathrm{L})$.

PGA/Chi and Alg/Chi films were notably thinner than others, an observation that matches previous reports. For example, Maurstad et al. have reported that greater compression of the chain and a larger degree of interpenetration occurs during the adsorption process of films comprising chitosan-polyanion as compared to those comprising PLLpolyanion because of differences in chain length and chain stiffness of the polycations [44]. Our ellipsometric measurement of thickness for $[\mathrm{Alg} / \mathrm{Chi}]_{6.5}$ was $41 \pm 5.0 \mathrm{~nm}$, which agrees with a previously reported estimate of $\sim 45 \mathrm{~nm}$ as measured by QCM [45].

As expected, we found that contact angles varied widely with film composition (Table 1); hence, each unique PEM architecture yielded different glucose permeability (Figure 2). While it is generally held that a high degree of film wettability increases the permeation of water-soluble substances in addition to promoting water flux [42,46], our observations did not indicate a strong direct correlation of glucose diffusion with contact angle (correlation coefficient, $\rho(C A, d C / d t)=-0.72$ ). For example, both Hep/Chi and DS/Chi were found to exhibit higher glucose permeation rates $(d C / d t)$ relative to DS/PLL despite similarly low contact angles.

As has been described for many synthetic PEMs, solution conditions $(\mathrm{pH}$, temperature, polyelectrolyte concentration, ionic strength) as well as degree of interdiffusion are expected to influence the transport property of multilayer films. That is, no single factor is strongly determinative for the diffusivity of small molecules through the films. 


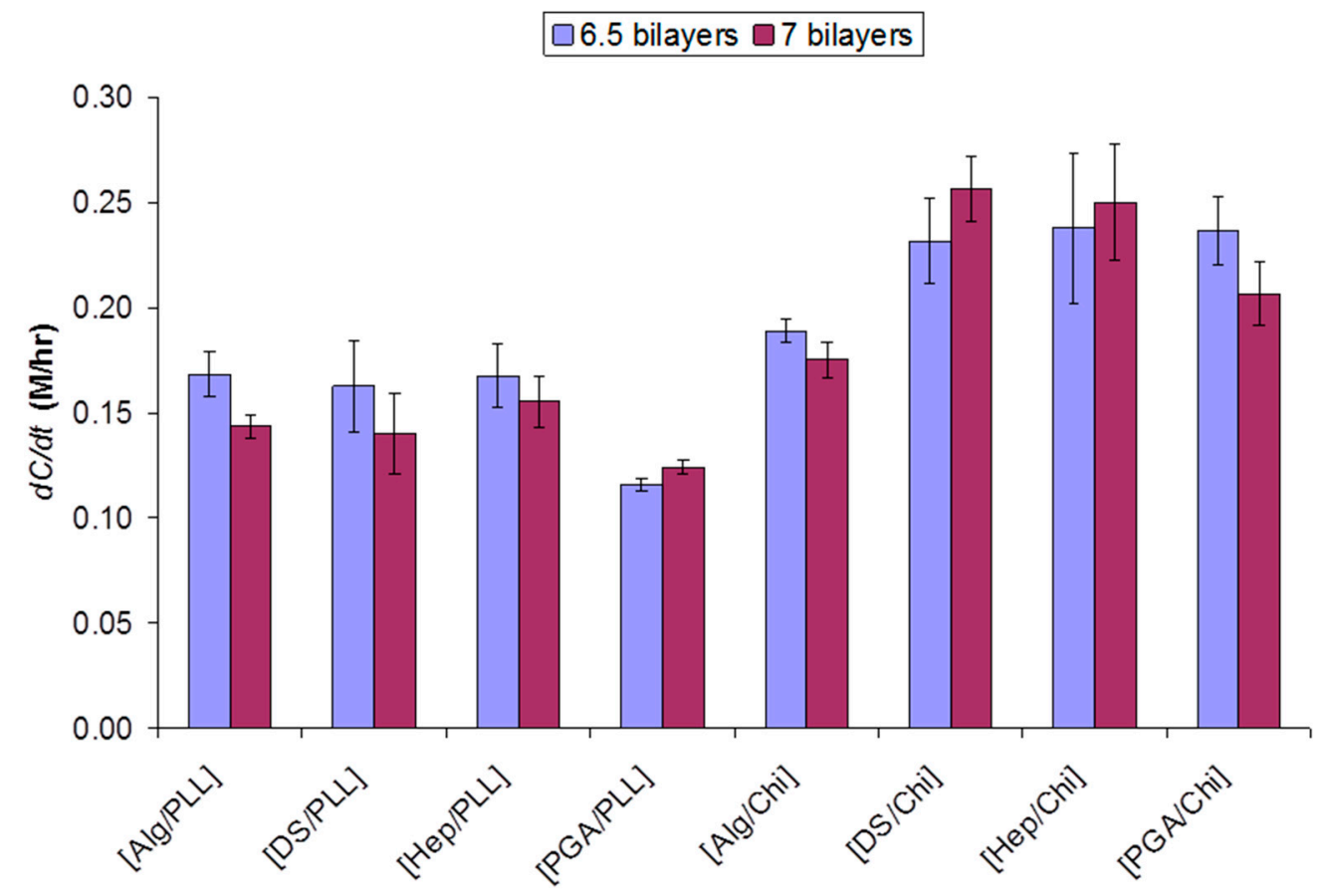

Figure 2. Permeate concentrations of glucose through the films were measured as a function of time $(d C / d t)$. Error bars indicate $95 \%$ confidence intervals $(n=3)$.

Crosslinking of polyelectrolyte multilayers has been used to provide stability of PEMs [34,35] as well as modify mechanical properties [36]. It has also been extensively applied for drug delivery applications [47]. A common approach to chemical crosslinking involves reaching carboxylic groups and amine groups inside the multilayer structure to form amide bonds [38]. While various linkers are available, the simplest protocols use "zero length" crosslinkers based on carbodiimide (EDC) chemistry to form new bonds and increase the strength of films without adding significant bulk or density. EDC is particularly attractive for use with BioPEMs because it may be used in mild aqueous conditions and does not require elevated temperature, oxygen removal, or UV exposure. Further, it may be used to crosslink any type of PEMs that contain nearby primary amine and carboxylate groups. Crosslinking of PGA/PLL, Alg/PLL, Hep/PLL, PGA/Chi, Hep/Chi, and $\mathrm{Alg} / \mathrm{Chi}$ was examined using Fourier transform infrared (FTIR) spectroscopy with an attenuated total reflectance (ATR) attachment to probe the ultrathin films (see Electronic Supplementary Information).

The thickness of each BioPEM film was compared before and after crosslinking (Figure 3). No difference in thickness was observed after crosslinking, except in the cases of PGA/Chi and Alg/Chi. In contrast, refractive indices were statistically different after crosslinking in most cases except $[\mathrm{Alg} / \mathrm{PLL}]_{7}$ and $[\mathrm{Hep} / \mathrm{Chi}]_{7}$ (see Electronic Supplementary Information). Interestingly, the thickness of the PGA/Chi film increased up to $61 \%$ after crosslinking, while the $\mathrm{Alg} / \mathrm{Chi}$ film decreased up to $43 \%$.

Based on these measurements, it appears that crosslinking induces internal structural changes in the PEMs. This is consistent with reports from Boulmedias et al. and Pilbat et al, who found that many PEMs - especially those containing one or more polypeptide component-exhibit secondary structures ( $\alpha$-helix and $\beta$-sheet) that take on different conformations depending on the environment as well as other film components (e.g., temperature, $\mathrm{pH}$, polyelectrolyte pair, etc.) $[48,49]$. Boudou et al. also reported that poly(allylamine hydrochloride)/PGA (PAH/PGA) films are structurally more dense and contain the highest density of carboxylic groups relative to other bioPEMs, such as Chi/hyaluronan (Chi/HA) and PLL/hyaluronan (PLL/HA) [50], suggesting that PGA has the greatest overall capacity for crosslinking. 


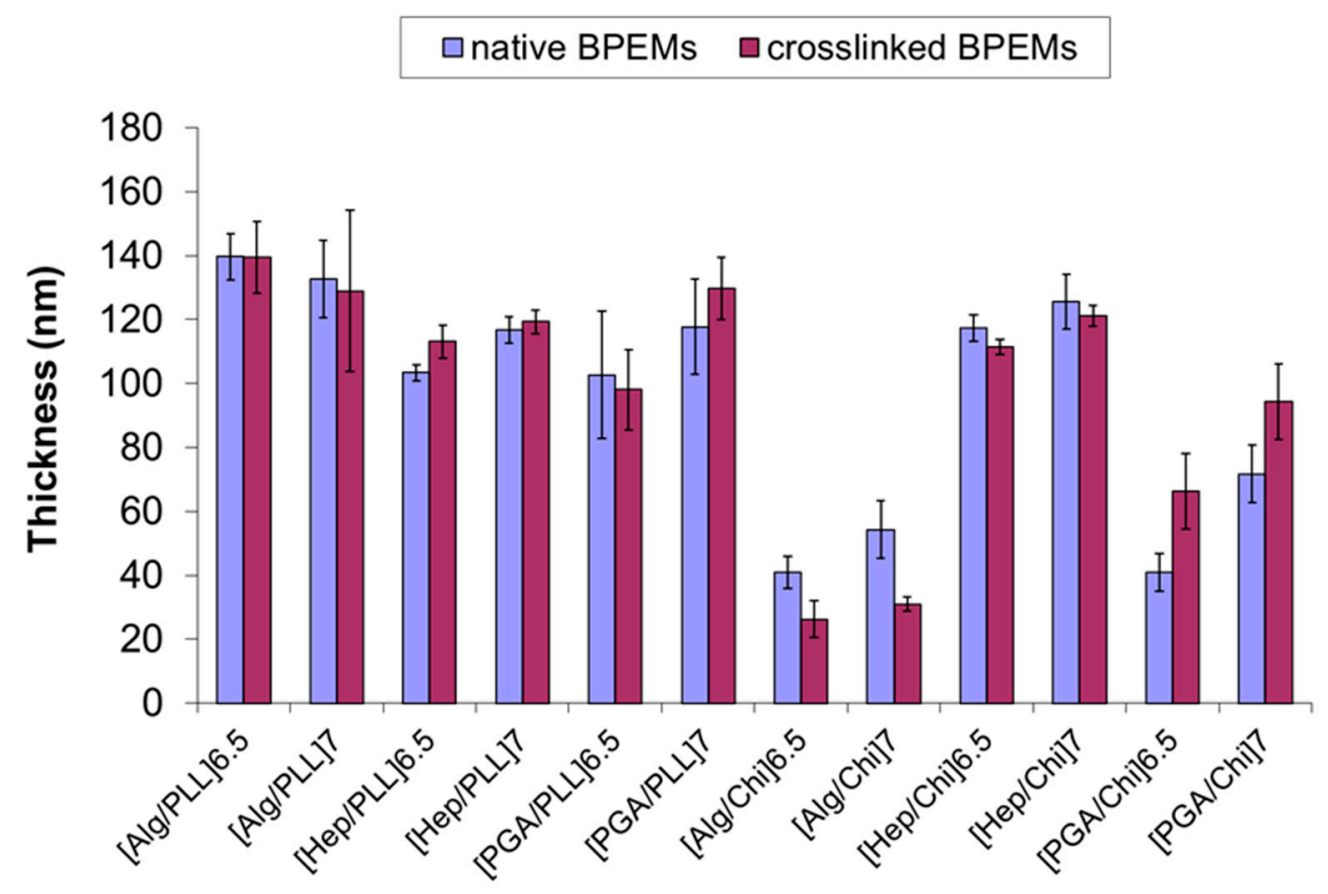

Figure 3. Nanofilm thickness before and after crosslinking of BioPEMs measured by ellipsometry. Error bars represent $95 \%$ confidence intervals $(\mathrm{n}=15)$.

Our results indicate that crosslinking between pairs of polyelectrolytes may result in a substantial conformational change in the internal structures of multilayers. The details of the final product may depend on multiple factors, such as the ratio of reacting side (carboxylic and amine) groups, as well as the stiffness of polymer chains and even secondary interactions of polymers within the films. Surface wettability of multilayer films also exhibited very different trends among various pairs of polyelectrolytes (Figure 4). Most Chi-based film structures increased in surface hydrophobicity after crosslinking, an expected result due to the very low contact angle of Chi-based materials; on the other hand, PLL-based films generally saw either a decreased contact angle after crosslinking or were statistically unaltered by the crosslinking reaction. For example, Hep/Chi and PGA/Chi exhibited increased contact angles, while PGA/PLL exhibited a significantly increased wettability contact angle after crosslinking. Even the terminal layer seems to play a role in how susceptible the PEMs are to crosslinking-induced changes; consider both Alg/PLL and Hep/PLL, where contact angles for 6.5 bilayers were statistically different after crosslinking, while no difference was observed $(\alpha=0.05)$ for 7 bilayers.

After crosslinking of BioPEMs, significant decreases in permeability were observed in Hep/Chi and PGA/Chi pairs (up to 47\% decrease in [Hep/Chi $]_{7}$ ) (Figure 5). As discussed earlier, increasing hydrophobicity decreases permeation of water-soluble substances in general. All crosslinked Hep/Chi and PGA/Chi pairs experienced a decrease in permeation rate up to $47 \%$ relative to native multilayer films, with accompanying significant increases in contact angles. However, neither increasing nor decreasing trends in permeability with other pairs of crosslinked BioPEMs were governed by the surface wettability of all the BioPEMs after crosslinking $(\rho(C A, d C / d t)=-0.44)$. It should also be noted that statistically equivalent glucose permeation was observed in many BioPEM pairs after crosslinking (e.g., $[\mathrm{Alg} / \mathrm{PLL}]_{6.5},[\mathrm{Alg} / \mathrm{PLL}]_{7},[\mathrm{Hep} / \mathrm{PLL}]_{6.5},[\mathrm{PGA} / \mathrm{PLL}]_{6.5},[\mathrm{Alg} / \mathrm{Chi}]_{6.5}$, and $[\mathrm{Alg} / \mathrm{Chi}]_{7}$ ). Based on these observations, there are no obvious trends, and it is notable that it is difficult to predict a priori how the properties of a nanofilm comprising a particular polyelectrolyte pair will change in response to crosslinking. Scatter plots (Figure S4) and more extensive correlation analysis did not reveal any quantitative relationship between these characteristics. 
Glucose diffusion coefficients $(D)$ for all the BioPEMs, including crosslinked films, were calculated based on experimentally measured thicknesses and permeation rates $(d C / d t)$ (Table 2). The $D$ values of BioPEMs were found to be up to four orders of magnitude lower than the $D$ value of bare substrate $\left(1.15 \times 10^{-6} \mathrm{~cm}^{2} / \mathrm{s}\right)$. However, these values are still one or two orders of magnitude higher than the previously reported glucose diffusion in synthetic polyelectrolyte multilayers, such as PSS/PAH and PAA/PAH [24].

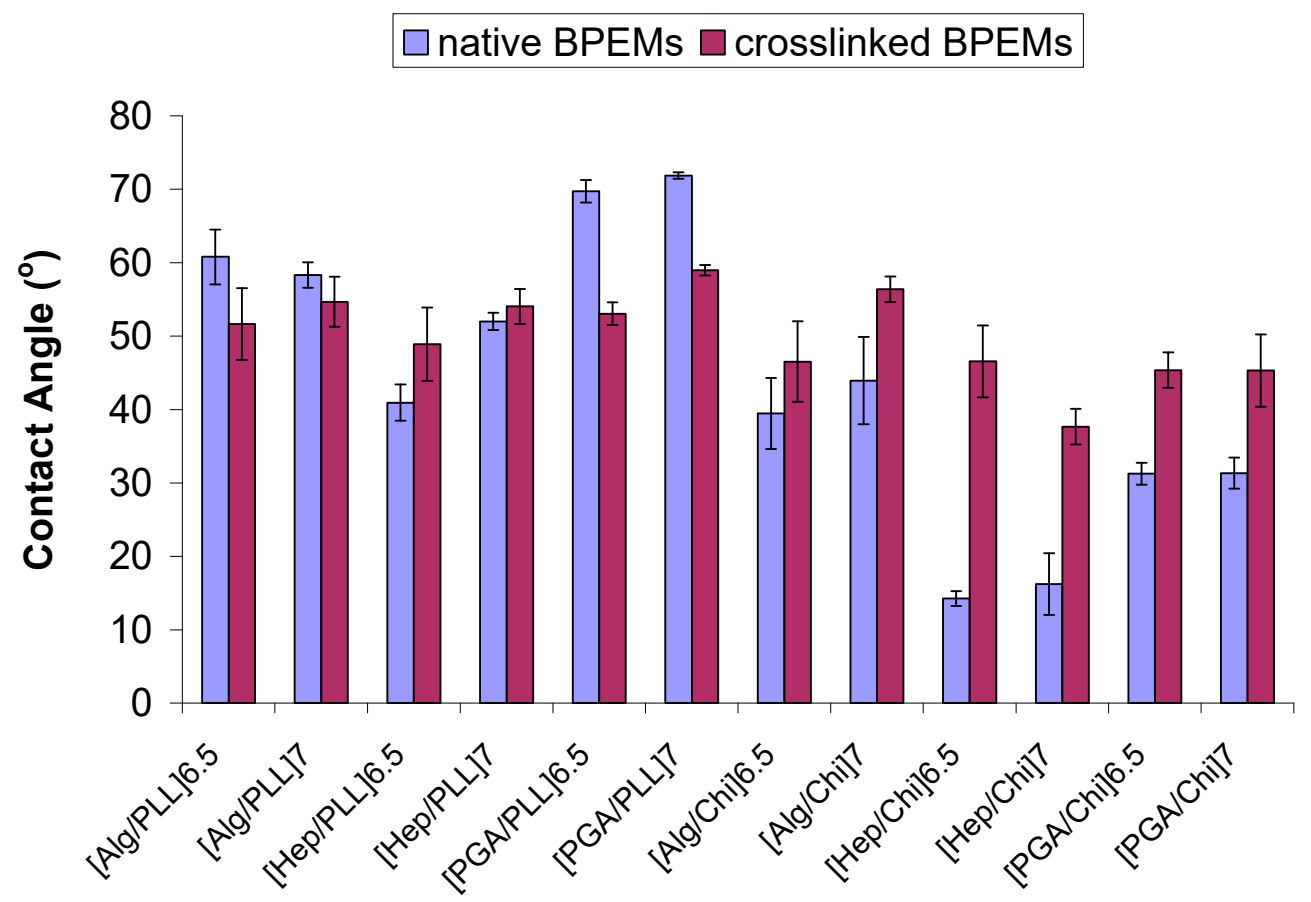

Figure 4. Static contact angles $\left(\theta_{\text {static }}\right)$ of nanofilms before and after crosslinking of BioPEMs. Error bars indicate $95 \%$ confidence intervals $(n=3)$.

\section{$\square$ native BPEMs $\square$ crosslinked BPEMs}

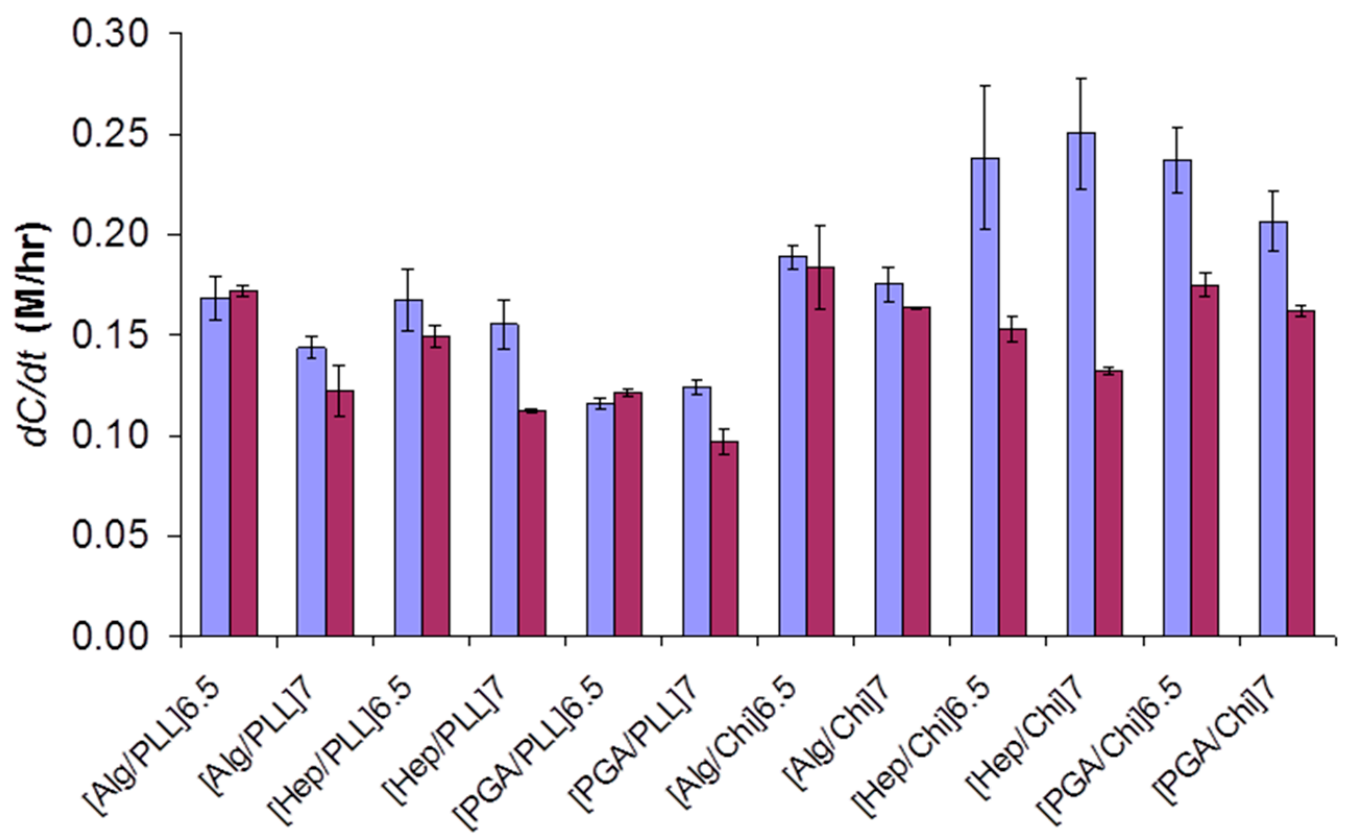

Figure 5. Permeation rate $(d C / d t)$ of glucose through various BioPEMs before and after chemical crosslinking. Error bars indicate $95 \%$ confidence intervals $(n=3)$. 
Table 2. Diffusion coefficients (D) of glucose through various BioPEMs.

\begin{tabular}{ccccc}
\hline \multirow{2}{*}{ Composition } & \multicolumn{4}{c}{$\mathbf{D}\left(\times \mathbf{1 0} \mathbf{- 1 0} \mathbf{~} \mathbf{m}^{\mathbf{2}} \mathbf{s} \mathbf{s}\right.$} \\
\cline { 2 - 5 } & \multicolumn{2}{c}{ Native BioPEMs } & \multicolumn{2}{c}{ Crosslinked BioPEMs } \\
\cline { 2 - 5 } & $\mathbf{6 . 5}$ Bilayers & $\mathbf{7 ~ B i l a y e r s ~}$ & $\mathbf{6 . 5}$ Bilayers & $\mathbf{7 ~ B i l a y e r s ~}$ \\
\hline [Alg/Chi] & $8.2( \pm 1.0)$ & $10.0( \pm 2.9)$ & $4.4( \pm 0.3)$ & $5.4( \pm 0.1)$ \\
[DS/Chi] & $19.1( \pm 1.7)$ & $27.4( \pm 1.6)$ & $\mathrm{n} / \mathrm{a}$ & $\mathrm{n} / \mathrm{a}$ \\
[Hep/Chi] & $29.4( \pm 3.7)$ & $33.5( \pm 8.6)$ & $17.7( \pm 0.4)$ & $17.1( \pm 0.7)$ \\
[PGA/Chi] & $10.3( \pm 3.0)$ & $15.7( \pm 4.4)$ & $10.6( \pm 3.9)$ & $16.2( \pm 3.2)$ \\
[Alg/PLL] & $24.8( \pm 1.5)$ & $20.1( \pm 2.2)$ & $24.9( \pm 4.5)$ & $16.5( \pm 5.7)$ \\
[DS/PLL] & $23.0( \pm 3.7)$ & $19.9( \pm 3.1)$ & $\mathrm{n} / \mathrm{a}$ & $\mathrm{n} / \mathrm{a}$ \\
[Hep/PLL] & $18.3( \pm 1.4)$ & $19.1( \pm 0.9)$ & $17.9( \pm 2.1)$ & $14.1( \pm 0.6)$ \\
[PGA/PLL] & $12.5( \pm 0.4)$ & $15.2( \pm 0.1)$ & $12.2( \pm 1.5)$ & $12.7( \pm 1.1)$ \\
\hline
\end{tabular}

Values were extracted by regression of flux and concentration gradient data using Fick's laws of diffusion. $\mathrm{D}$ value through bare substrate is $1.15 \times 10^{-6} \mathrm{~cm}^{2} / \mathrm{s}$. Shown in parentheses are $95 \%$ confidence intervals $(\mathrm{n}=3)$.

Although all the BioPEMs possess higher glucose permeability than synthetic PEMs, they can maximize the biomimetic properties at the interface while limiting transport of the small molecule over the range of interest.

\section{Conclusions}

There has been considerable development of biomimetic self-assembly over the recent past, especially with the exploration of PEM films with novel compositions to realize biomaterial surfaces with precise compositional and structural features [32]. Among the properties with which PEMs may endow materials, coatings that limit transport of small molecules are particularly attractive for devices that deliver or react with physiologically relevant species. While coatings comprising synthetic PEMs have been widely investigated for the potential to control transport of small molecules, this has not been studied for natural or biomimetic polyelectrolytes $[24,33]$.

Thus, this work investigated the construction of BioPEMs, their resulting physical properties, and their respective glucose diffusion characteristics. In all cases, glucose diffusivity of these BioPEMs, including both native and their crosslinked forms, were three to four orders of magnitude lower than what was measured for bare substrates. Crosslinking BioPEMs decreased the diffusivity of glucose by up to $51 \%$ as compared to the native BioPEMs. However, all $D$ values were still well above values previously reported for synthetic polyelectrolyte multilayers such as PSS/PAH and PAA/PAH. Upon assessment of the correlation between general multilayer properties, it was found that the permeability of BioPEMs mainly depends on the component materials of BioPEMs; no general trends governing correlation of film characteristics (i.e., contact angle, thickness, and crosslinking) and permeation rate were observed.

These general observations for a special class of PEMs may be useful in designing future biomimetic materials, wherein small molecule transport may be controlled by an ultra-thin coating presenting a bio-friendly interface. It is also anticipated that the system developed for determining transport properties of PEMs or other coatings will provide a general platform for assessing candidate materials in a broad range of chemical and biological systems, from analytical separation to biomedical applications. For future work, further studies of specific BioPEM coatings will reveal biodegradation, biostability, and biofouling.

Supplementary Materials: The following are available online at https:/ / www.mdpi.com/article/ 10.3390/coatings11091024/s1, Figure S1: ATR FT-IR spectra of [PLL/Alg]7, [PLL/Hep]7, and $[\mathrm{PLL} / \mathrm{PGA}]_{7}$ before and after crosslinking of BPEMs; Figure S2: ATR FT-IR spectra of [Chi/Alg $]_{7}$, $\left[\mathrm{Chi} / \mathrm{Hep}_{7}\right.$, and $[\mathrm{Chi} / \mathrm{PGA}]_{7}$ before and after crosslinking of BPEMs; Figure S3: Refractive indices before and after crosslinking of BPEMs measured by ellipsometry; Figure S4: Scatter plots of diffusion coefficient versus contact angle before and after crosslinking. 
Author Contributions: Conceptualization, M.J.M.; methodology, J.P. and M.J.M.; software, M.J.M.; validation, J.P. and M.J.M.; formal analysis, J.P. and M.J.M.; resources, M.J.M.; writing-original draft preparation, J.P.; writing-review and editing, J.P. and M.J.M.; supervision, M.J.M.; project administration, M.J.M.; funding acquisition, M.J.M. All authors have read and agreed to the published version of the manuscript.

Funding: This research was funded by the National Science Foundation, grant number BES-060037. Any opinions, findings, and conclusions or recommendations expressed in this material are those of the author(s) and do not necessarily reflect the views of the National Science Foundation.

Institutional Review Board Statement: Not applicable.

Informed Consent Statement: Not applicable.

Data Availability Statement: Not applicable.

Acknowledgments: Ellipsometry was performed at the TAMU Materials Characterization Facility.

Conflicts of Interest: The authors declare no conflict of interest. The funders had no role in the design of the study; in the collection, analyses, or interpretation of data; in the writing of the manuscript, or in the decision to publish the results.

\section{References}

1. Gough, D.A.; Lucisano, J.Y.; Tse, P.H.S. Two-Dimensional Enzyme Electrode Sensor for Glucose. Anal. Chem. 1985, 57, $2351-2357$. [CrossRef]

2. Ladam, G.; Schaaf, P.; Decher, G.; Voegel, J.-C.; Cuisinier, F.J.G. Protein adsorption onto auto-assembled polyelectrolyte films. Biomol. Eng. 2002, 19, 273-280. [CrossRef]

3. Anderson, J.M. Biomaterials Science, 1st ed.; Ratner, B., Hoffman, A., Schoen, F., Lemons, J., Eds.; Academic Press: Cambridge, UK, 1996; pp. 165-173.

4. Decher, G.; Lvov, Y.; Schmitt, J. Proof of multilayer structural organization in self-assembled polycation-polyanion molecular films. Thin Solid Film. 1994, 244, 772-777. [CrossRef]

5. Decher, G. Fuzzy Nanoassemblies: Toward Layered Polymeric Multicomposites. Science 1997, 277, 1232-1237. [CrossRef]

6. Decher, G.; Schlenoff, J.B. (Eds.) Multilayer Thin Films: Sequential Assembly of Nanocomposite Materials, 1st ed.; Wiley-VCH: Weinheim, Germany, 2003; p. 543.

7. Lvov, Y.M.; Sukhorukov, G.B. Protein architecture: Assembly of ordered films by means of alternated adsorption of oppositely charged macromolecules. Membr. Cell Biol. 1997, 11, 277-303.

8. Sano, M.; Lvov, Y.; Kunitake, T. Formation of Ultrathin Polymer Layers on Solid Substrates by Means of Polymerization-Induced Epitaxy and Alternate Adsorption. Annu. Rev. Mater. Sci. 1996, 26, 153-187. [CrossRef]

9. Lvov, Y.; Ariga, K.; Onda, M.; Ichinose, I.; Kunitake, T. Alternate Assembly of Ordered Multilayers of $\mathrm{SiO}_{2}$ and Other $\mathrm{Nanoparticles}$ and Polyions. Langmuir 1997, 13, 6195-6203. [CrossRef]

10. Lvov, Y.; Ariga, K.; Ichinose, I.; Kunitake, T. Assembly of Multicomponent Protein Films by Means of Electrostatic Layer-by-Layer Adsorption. J. Am. Chem. Soc. 1995, 117, 6117-6123. [CrossRef]

11. Keller, S.W.; Kim, H.-N.; Mallouk, T.E. Layer-by-Layer Assembly of Intercalation Compounds and Heterostructures on Surfaces: Toward Molecular “Beaker" Epitaxy. J. Am. Chem. Soc. 1994, 116, 8817-8818. [CrossRef]

12. Kotov, N.A.; Dekany, I.; Fendler, J.H. Layer-by-Layer Self-Assembly of Polyelectrolyte-Semiconductor Nanoparticle Composite Films. J. Phys. Chem. 1995, 99, 13065-13069. [CrossRef]

13. Schüler, C.; Caruso, F. Preparation of enzyme multilayers on colloids for biocatalysis. Macromol. Rapid Commun. 2000, 21, 750-753. [CrossRef]

14. Anzai, J.-i.; Takeshita, H.; Kobayashi, Y.; Osa, T.; Hoshi, T. Layer-by-Layer Construction of Enzyme Multilayers on an Electrode for the Preparation of Glucose and Lactate Sensors: Elimination of Ascorbate Interference by Means of an Ascorbate Oxidase Multilayer. Anal. Chem. 1998, 70, 811-817. [CrossRef] [PubMed]

15. Hoshi, T.; Saiki, H.; Kuwazawa, S.; Tsuchiya, C.; Chen, Q.; Anzai, J.i. Selective Permeation of Hydrogen Peroxide through Polyelectrolyte Multilayer Films and Its Use for Amperometric Biosensors. Anal. Chem. 2001, 73, 5310-5315. [CrossRef] [PubMed]

16. Lvov, Y.; Antipov, A.A.; Mamedov, A.; Möhwald, H.; Sukhorukov, G.B. Urease Encapsulation in Nanoorganized Microshells. Nano Lett. 2001, 1, 125-128. [CrossRef]

17. Boura, C.; Menu, P.; Payan, E.; Picart, C.; Voegel, J.C.; Muller, S.; Stoltz, J.F. Endothelial cells grown on thin polyelectrolyte mutlilayered films: An evaluation of a new versatile surface modification. Biomaterials 2003, 24, 3521-3530. [CrossRef]

18. Fu, J.; Ji, J.; Yuan, W.; Shen, J. Construction of anti-adhesive and antibacterial multilayer films via layer-by-layer assembly of heparin and chitosan. Biomaterials 2005, 26, 6684-6692. [CrossRef]

19. Thompson, M.T.; Berg, M.C.; Tobias, I.S.; Rubner, M.F.; Van Vliet, K.J. Tuning compliance of nanoscale polyelectrolyte multilayers to modulate cell adhesion. Biomaterials 2005, 26, 6836-6845. [CrossRef] 
20. Buck, M.E.; Breitbach, A.S.; Belgrade, S.K.; Blackwell, H.E.; Lynn, D.M. Chemical modification of reactive multilayered films fabricated from poly(2-alkenyl azlactone)s: Design of surfaces that prevent or promote mammalian cell adhesion and bacterial biofilm growth. Biomacromolecules 2009, 10, 1564-1574. [CrossRef] [PubMed]

21. Boudou, T.; Crouzier, T.; Nicolas, C.; Ren, K.; Picart, C. Polyelectrolyte Multilayer Nanofilms Used as Thin Materials for Cell Mechano-Sensitivity Studies. Macromol. Biosci. 2011, 11, 77-89. [CrossRef] [PubMed]

22. Rodrigues, S.N.; Gonçalves, I.C.; Martins, M.C.L.; Barbosa, M.A.; Ratner, B.D. Fibrinogen adsorption, platelet adhesion and activation on mixed hydroxyl-/methyl-terminated self-assembled monolayers. Biomaterials 2006, 27, 5357-5367. [CrossRef] [PubMed]

23. Chen, H.; Hu, X.; Zhang, Y.; Li, D.; Wu, Z.; Zhang, T. Effect of chain density and conformation on protein adsorption at PEG-grafted polyurethane surfaces. Colloids Surf. B Biointerfaces 2008, 61, 237-243. [CrossRef] [PubMed]

24. Park, J.; McShane, M.J. DualFunction Nanofilm Coatings with Diffusion Control and Protein Resistance. ACS Appl. Mater. Interfaces 2010, 2, 991-997. [CrossRef] [PubMed]

25. Tang, L.; Thevenot, P.; Hu, W. Surface Chemistry Influences Implant Biocompatibility. Curr. Top. Med. Chem. 2008, 8, 270-280. [CrossRef]

26. Boulmedais, F.; Frisch, B.; Etienne, O.; Lavalle, P.; Picart, C.; Ogier, J.; Voegel, J.C.; Schaaf, P.; Egles, C. Polyelectrolyte multilayer films with pegylated polypeptides as a new type of anti-microbial protection for biomaterials. Biomaterials 2004, 25, $2003-2011$. [CrossRef] [PubMed]

27. Stein, E.W.; Singh, S.; McShane, M.J. Microscale Enzymatic Optical Biosensors Using Mass Transport Limiting Nanofilms. 2. Response Modulation by Varying Analyte Transport Properties. Anal. Chem. 2008, 80, 1408-1417. [CrossRef] [PubMed]

28. Stein, E.W.; Grant, P.S.; Zhu, H.; McShane, M.J. Microscale Enzymatic Optical Biosensors Using Mass Transport Limiting Nanofilms. 1. Fabrication and Characterization Using Glucose as a Model Analyte. Anal. Chem. 2007, 79, 1339-1348. [CrossRef]

29. Gerritsen, M.; Jansen, J.A.; Lutterman, J.A. Performance of subcutaneously implanted glucose sensors for continuous monitoring. Neth. J. Med. 1999, 54, 167-179. [CrossRef]

30. Koppolu, B.; Rahimi, M.; Nattama, S.; Wadajkar, A.; Nguyen, K.T. Development of multiple-layer polymeric particles for targeted and controlled drug delivery. Nanomedicine 2010, 6, 355-361. [CrossRef] [PubMed]

31. Wang, C.; Ye, W.; Zheng, Y.; Liu, X.; Tong, Z. Fabrication of drug-loaded biodegradable microcapsules for controlled release by combination of solvent evaporation and layer-by-layer self-assembly. Int. J. Pharm. 2007, 338, 165-173. [CrossRef]

32. Boudou, T.; Crouzier, T.; Ren, K.; Blin, G.; Picart, C. Multiple Functionalities of Polyelectrolyte Multilayer Films: New Biomedical Applications. Adv. Mater. 2010, 22, 441-467. [CrossRef]

33. Liu, X.; Bruening, M.L. Size-Selective Transport of Uncharged Solutes through Multilayer Polyelectrolyte Membranes. Chem. Mater. 2004, 16, 351-357. [CrossRef]

34. Johansson, J.A.; Halthur, T.; Herranen, M.; Soderberg, L.; Elofsson, U.; Hilborn, J. Build-up of collagen and hyaluronic acid polyelectrolyte multilayers. Biomacromolecules 2005, 6, 1353-1359. [CrossRef]

35. Etienne, O.; Schneider, A.; Taddei, C.; Richert, L.; Schaaf, P.; Voegel, J.-C.; Egles, C.; Picart, C. Degradability of Polysaccharides Multilayer Films in the Oral Environment: An In Vitro and In Vivo Study. Biomacromolecules 2005, 6, 726-733. [CrossRef]

36. Collin, D.; Lavalle, P.; Garza, J.M.; Voegel, J.-C.; Schaaf, P.; Martinoty, P. Mechanical properties of cross-linked hyaluronic acid/poly-(L-lysine) multilayer films. Macromolecules 2004, 37, 10195-10198. [CrossRef]

37. Sauerbrey, G. Verwendung von Schwingquarzen zur Wägung dünner Schichten und zur Mikrowägung. Z. Für Phys. A Hadron. Nucl. 1959, 155, 206-222. [CrossRef]

38. Richert, L.; Boulmedais, F.; Lavalle, P.; Mutterer, J.; Ferreux, E.; Decher, G.; Schaaf, P.; Voegel, J.-C.; Picart, C. Improvement of Stability and Cell Adhesion Properties of Polyelectrolyte Multilayer Films by Chemical Cross-Linking. Biomacromolecules 2004, 5, 284-294. [CrossRef] [PubMed]

39. Raabo, E.; Terkildsen, T.C. On the Enzymatic Determination of Blood Glucose. Scand. J. Clin. Lab. Investig. 1960, 12, 402-407. [CrossRef]

40. Elbert, D.L.; Herbert, C.B.; Hubbell, J.A. Thin Polymer Layers Formed by Polyelectrolyte Multilayer Techniques on Biological Surfaces. Langmuir 1999, 15, 5355-5362. [CrossRef]

41. Lavalle, P.; Gergely, C.; Cuisinier, F.J.G.; Decher, G.; Schaaf, P.; Voegel, J.C.; Picart, C. Comparison of the Structure of Polyelectrolyte Multilayer Films Exhibiting a Linear and an Exponential Growth Regime: An In Situ Atomic Force Microscopy Study. Macromolecules 2002, 35, 4458-4465. [CrossRef]

42. Dai, J.; Jensen, A.W.; Mohanty, D.K.; Erndt, J.; Bruening, M.L. Controlling the Permeability of Multilayered Polyelectrolyte Films through Derivatization, Cross-Linking, and Hydrolysis. Langmuir 2001, 17, 931-937. [CrossRef]

43. Liu, H.; Faucher, K.M.; Sun, X.-L.; Feng, J.; Johnson, T.L.; Orban, J.M.; Apkarian, R.P.; Dluhy, R.A.; Chaikof, E.L. A MembraneMimetic Barrier for Cell Encapsulation. Langmuir 2002, 18, 1332-1339. [CrossRef]

44. Maurstad, G.; Mørch, Y.A.; Bausch, A.R.; Stokke, B.T. Polyelectrolyte layer interpenetration and swelling of alginate-chitosan multilayers studied by dual wavelength reflection interference contrast microscopy. Carbohydr. Polym. 2008, 71, 672-681. [CrossRef]

45. Alves, N.M.; Picart, C.; Mano, J.F. Self Assembling and Crosslinking of Polyelectrolyte Multilayer Films of Chitosan and Alginate Studied by QCM and IR Spectroscopy. Macromol. Biosci. 2009, 9, 776-785. [CrossRef] [PubMed] 
46. Glinel, K.; Prevot, M.; Krustev, R.; Sukhorukov, G.B.; Jonas, A.M.; Mohwald, H. Control of the water permeability of polyelectrolyte multilayers by deposition of charged paraffin particles. Langmuir 2004, 20, 4898-4902. [CrossRef] [PubMed]

47. Schneider, A.; Vodouhê, C.; Richert, L.; Francius, G.; Le Guen, E.; Schaaf, P.; Voegel, J.-C.; Frisch, B.; Picart, C. Multifunctional Polyelectrolyte Multilayer Films: Combining Mechanical Resistance, Biodegradability, and Bioactivity. Biomacromolecules 2006, 8 , 139-145. [CrossRef]

48. Boulmedais, F.; Bozonnet, M.; Schwinte, P.; Voegel, J.C.; Schaaf, P. Multilayered polypeptide films: Secondary structures and effect of various stresses. Langmuir 2003, 19, 9873-9882. [CrossRef]

49. Pilbat, A.M.; Ball, V.; Schaaf, P.; Voegel, J.C.; Szalontai, B. Partial poly(glutamic acid) <-> poly(aspartic acid) exchange in layer-by-layer polyelectrolyte films. Structural alterations in the three-component architectures. Langmuir 2006, 22, 5753-5759. [CrossRef]

50. Boudou, T.; Crouzier, T.; Auzély-Velty, R.; Glinel, K.; Picart, C. Internal Composition versus the Mechanical Properties of Polyelectrolyte Multilayer Films: The Influence of Chemical Cross-Linking. Langmuir 2009, 25, 13809-13819. [CrossRef] 